\title{
A Heuristic Approach to the Diagnosis of Transformer's Insulating Oil
}

\author{
Ming-Jong Lin \\ Department of Electronic Engineering, Southern Taiwan University of Science and Technology, \\ Tainan City, Taiwan \\ Email: 1430107@yahoo.com.tw
}

Received January 2014

\section{Abstract}

The transformer plays so important equipment in power system that engineers take more measures on the insulating oil of transformer by diagnosis. The dissolved gas analysis (DGA) is an effective technique for detecting incipient faults in oil-immersed power transformers. So the paper investigates the DGA methods, while employ the ANSI/IEEE C57.104 standards and the Key Gas diagnosis rules as base to develop a fast transformer fault diagnosis method in practice. I designed a report's form which was so easy to understand that we can have accurate diagnosis what was up in the body of transformer by EXCEL programmed. The user only keys in the measured data of main gases including $\mathrm{CO}, \mathrm{H}_{2}, \mathrm{CH}_{4}, \mathrm{C}_{2} \mathrm{H}_{2}, \mathrm{C}_{2} \mathrm{H}_{4}$, and $\mathrm{C}_{2} \mathrm{H}_{6}$ those gases were taken from ASTM D3612's instruction. Then the diagnosis result was showed in texts and the plotted figures which were two figures to compare diagnosis the test's figure with the reference figure of the Key Gas diagnosis rules that was taken the analysis of transformer fault from over past in power system. Last but not least, the proposal offers a simple, quick, and an accurate of diagnosis through human-ma- chine interface. While which was been quickly, simply, and accurately proved on October $25^{\text {th }}, 2012$ Nan Cou E/S \#4 ATr's insulating oil of diagnosis.

\section{Keywords}

Power Transformer Diagnosis; Dissolved Gas Analysis; Total Combustible Gases

\section{Introduction}

Transformers in the power system plays an important role as voltage conversion, if the analysis of insulating oil mistaken or missed testing that it will bring up transformer fault which will be either a small area or a wide area of interruption electricity more than shut down exchange stock market. The analysis of insulating oil can diagnose what was up in body of the transformer in advance, thus it was regarded as an important diagnosis tool. In practice all over the world power company has been widely used. Transformer insulating oil has to more than one to be detected every year. Insulating oil may decompose under the influence of thermal and electrical stresses, and in doing so, yield gaseous decomposition products of varying composition which dissolve in the insulating oil. The nature and amount of the individual component gases that may be recovered and analyzed may be indicative of the type and degree of the abnormality responsible for the gas generation. The rate of gas 
generation and changes in concentration of specific gases over time are also used to evaluate the condition of the electric instrument.

When it is detected via decomposition chromatography (ASTM D3612) which will been found nine kind of gas, such as Ethane $\left(\mathrm{C}_{2} \mathrm{H}_{6}\right)$, Hydrogen $\left(\mathrm{H}_{2}\right)$, Methane $\left(\mathrm{CH}_{4}\right)$, Carbon Dioxide $\left(\mathrm{CO}_{2}\right)$, Ethylene $\left(\mathrm{C}_{2} \mathrm{H}_{4}\right)$, Acetylene $\left(\mathrm{C}_{2} \mathrm{H}_{2}\right)$, Carbon Monoxide (CO), Nitrogen $\left(\mathrm{N}_{2}\right)$, and Oxygen $\left(\mathrm{O}_{2}\right)$ [1] [2].

Then Hydrogen $\left(\mathrm{H}_{2}\right)$, Methane $\left(\mathrm{CH}_{4}\right)$, Ethane $\left(\mathrm{C}_{2} \mathrm{H}_{6}\right)$, Ethylene $\left(\mathrm{C}_{2} \mathrm{H}_{4}\right)$, Acetylene $\left(\mathrm{C}_{2} \mathrm{H}_{2}\right)$, and Carbon Monoxide (CO) were been added that was named combustible gas (Total Combustible Gases, TCG), if any gas containing is over the standard value, the transformer has to tracking or fulfilling to identify the safety of operation. This abnormal phenomenon threatens the Transformer operate normally. Based on a stable power supply and equipment safety, which is a great problem for maintenance engineer to deal with accuracy diagnosis the quality of insulating oil of transformer.

For accuracy to diagnose the transformer's insulating oil, taking the major diagnosis of the specification of the ANSI/IEEE C57.104 Standard and the Key Gas diagnosis rules [3] those were designed for a report form by program of EXCEL that can eliminates human error and misjudgment, on this paper; it was proved for accuracy of diagnosis of the transformer operation status.

\section{Transformer Fault Diagnosis}

Combustible gas total made up of $\mathrm{H}_{2}, \mathrm{CH}_{2}, \mathrm{C}_{2} \mathrm{H}_{6}, \mathrm{C}_{2} \mathrm{H}_{4}, \mathrm{C}_{2} \mathrm{H}_{2}$, $\mathrm{CO}$ [3], its definition as follows, as shown in Formula (1) (unit ppm):

$$
T C G=\frac{\mathrm{H}_{2}+\mathrm{CH}_{2}+\mathrm{C}_{2} \mathrm{H}_{6}+\mathrm{C}_{2} \mathrm{H}_{4}+\mathrm{C}_{2} \mathrm{H}_{2}+\mathrm{CO}}{10^{6}}
$$

The insulating oil along with the transformer operating time and the measured of the cyclical time has makes the relations, however its increase value on IEEE C57.104 standard, as shown in Formula (2):

$$
R=\frac{\left(S_{T}-S_{O}\right) \times V \times 10^{-6}}{T}
$$

$R$ is increase of the TCG value (a milliliter/day), $\mathrm{ST}$ is testing value, $\mathrm{S}_{\mathrm{O}}$ is previous value, $\mathrm{V}$ was measured the transformer's volume as well as $\mathrm{T}$ is measured the duration of days. The TCG, rely on the R's value which is classified “Normal”, “Attention”, “Abnormal”, and “Overhaul” etc. four kind of symptom (in Table 1).

Be based on Dissolved Gas Analysis (DGA), the value of insulating oil has been diagnosed normality or abnormality in the body of transformer.s In recent years, a number of techniques have been developed to predict

\begin{tabular}{|c|c|c|c|c|}
\hline & TCG & Increase & Again measures duration & suggestion \\
\hline \multirow{3}{*}{ Case 1} & \multirow{3}{*}{$\leq 720$} & $>30$ & month & Normal \\
\hline & & $10-30$ & season & Normal \\
\hline & & $<10$ & year & Normal \\
\hline \multirow{3}{*}{ Case 2} & \multirow{3}{*}{$721-1920$} & $>30$ & month & Attention \\
\hline & & $10-30$ & month & Attention \\
\hline & & $<10$ & season & Attention \\
\hline \multirow{3}{*}{ Case 3} & \multirow{3}{*}{$1921-4630$} & $>30$ & week & Abnormal \\
\hline & & $10-30$ & week & Abnormal \\
\hline & & $<10$ & month & Abnormal \\
\hline \multirow{3}{*}{ Case 4} & \multirow{3}{*}{$>4630$} & $>30$ & day & Overhaul \\
\hline & & $10-30$ & day & Overhaul \\
\hline & & $<10$ & week & Overhaul \\
\hline
\end{tabular}

Table 1. Periodic table of examination for TCG [4] unit: ppm. 
diagnosis for the transformer latent failure points by the gas content, such as the Key Gas method [2]-[5], Duval triangle method as well as Dornenberg method, Roger method, etc., the paper took the Key Gas diagnosis rules and ANSI/IEEE standards diagnosis rules to design a report form by the EXCEL program which described next sections below.

\subsection{The Key Gas Method}

Transformer fault types were linked with occurrence site and the gas composition of insulating oil, (in Figure 1) shows four typical fault types, namely: 1) Overheating because the insulating oil or insulating paper aging deterioration occurs, then it was decomposed dominating of $\mathrm{C}_{2} \mathrm{H}_{4}, \mathrm{C}_{2} \mathrm{H}_{6}$, and doped with $\mathrm{CH}_{4} ; 2$ ) Corona was decomposed mainly $\mathrm{H}_{2}$ and $\mathrm{CH}_{4}$; 3) Arcing was decomposed mainly $\mathrm{H}_{2}$ and $\mathrm{C}_{2} \mathrm{H}_{2}$; 4) Paper Fiber Overheating was decomposed mainly CO. By insulating oil composed to diagnosis transformer fault that were called "Key Gas method" [3].
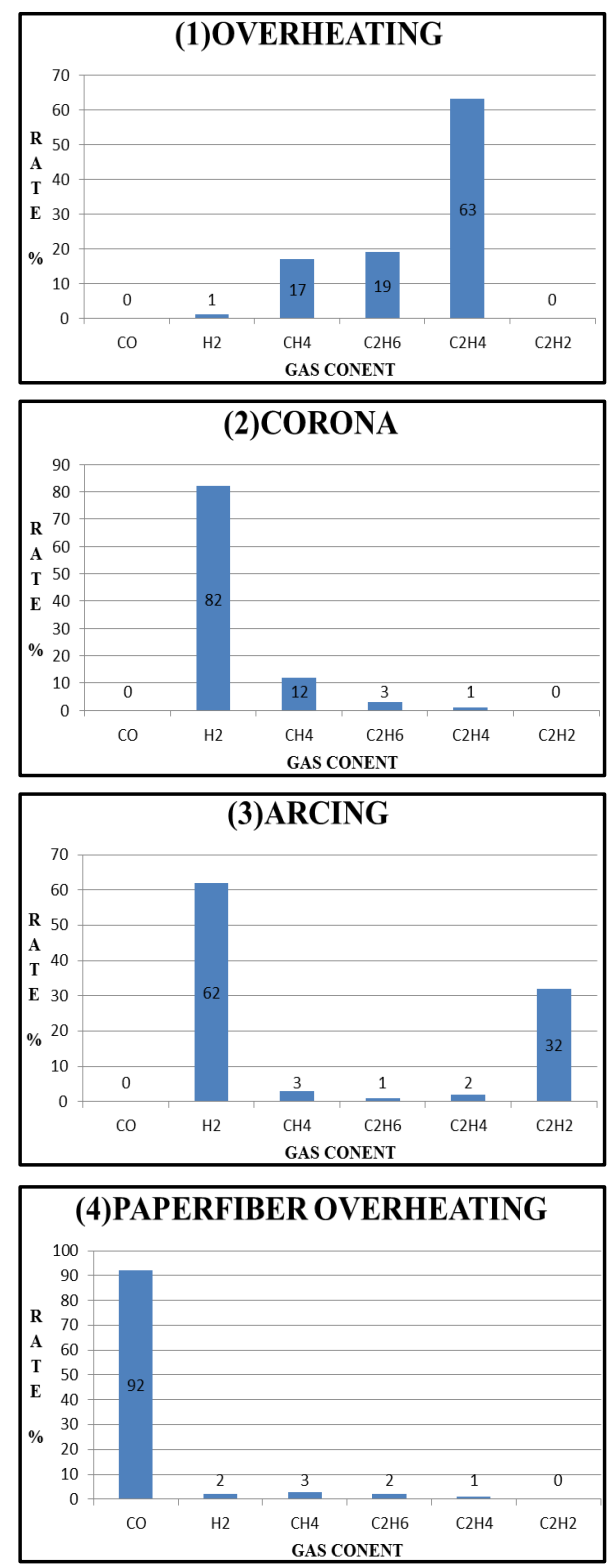

Figure 1. The gas content of typical faults proportion. 


\subsection{Duval Trigonometry}

Duval triangulation method is from decomposed of the insulating oil taking $\mathrm{CH}_{4}, \mathrm{C}_{2} \mathrm{H}_{4}$ and $\mathrm{C}_{2} \mathrm{H}_{2}$ to construct a triangle which made relationship between the ratio of two gases (in Figure 2), according to the ratio is divided into seven blocks, each block represent a fault zones, namely: PD Partial Discharge fault zone, T1 Overheating fault zone temperature is less than $300^{\circ} \mathrm{C}$, T2 moderate Overheating fault zone temperature in between $300^{\circ} \mathrm{C}$ and $700^{\circ} \mathrm{C}$, T3 Overheating fault zone temperature is greater than the height of $700^{\circ} \mathrm{C}$, D1 low energy Discharge fault zone, D2 district high energy Discharge (Arcing) faults, DT district mixture of electrical and Thermal faults. This method had used for the early detection of a transformer fault diagnosis tool.

\subsection{Dornenburg Method}

Dornenburg method takes the insulating oil by decomposition of $\mathrm{H}_{2}, \mathrm{CH}_{2}, \mathrm{C}_{2} \mathrm{H}_{6}, \mathrm{C}_{2} \mathrm{H}_{4}$, and $\mathrm{C}_{2} \mathrm{H}_{2}$, etc. Those were compared with $\mathrm{CH}_{4} / \mathrm{H}_{2}, \mathrm{C}_{2} \mathrm{H}_{2} / \mathrm{C}_{2} \mathrm{H}_{4}, \mathrm{C}_{2} \mathrm{H}_{2} / \mathrm{CH}_{4}$, and $\mathrm{C}_{2} \mathrm{H}_{6} / \mathrm{C}_{2} \mathrm{H}_{2}$ each other. Resulting, it is divided into Thermal decomposition, Partial Discharge, and Arcing, three fault types.

\subsection{Roger Methods}

Roger method is the use of insulating oil from the decomposition of $\mathrm{H}_{2}, \mathrm{CH}_{2}, \mathrm{C}_{2} \mathrm{H}_{6}, \mathrm{C}_{2} \mathrm{H}_{4}$, and $\mathrm{C}_{2} \mathrm{H}_{2}$ five gas content values corresponding to the ratio between the size to distinguish between normal, low-energy Arc, high energy Arc, low heat $\left(300^{\circ} \mathrm{C}\right)$, the Overheating $\left(<700^{\circ} \mathrm{C}\right)$, high heat $\left(>700^{\circ} \mathrm{C}\right)$, six kinds of diagnostic type.

\subsection{Japan Electric Association}

Japan Electric Association- “Gas pattern diagnosis” and "Specific gas diagnosis” rules [5]. In addition to the several diagnostic methods, there IEC basic gas Ratio rule, the equivalent overheating area method [2], and so on, all kinds of diagnostic methods has its advantages and disadvantages, because of space so that were not to show each, this article will use the industry's widespread usage of ANSI/IEEE C57.104 specification diagnostic method and Japan Electric Association- “Gas pattern diagnosis” and "Specific gas diagnosis” rules to design a highly and simply diagnosis method.

PD: indicates partial discharge

D1: discharge of low energy arcing

D2: discharge of high energy arcing

DT: attributes to mixture of electrical and thermal faults

T1: the zone of low thermal fault $\mathrm{C}_{2} \mathrm{H} 2 \%=100 \mathrm{X} / \mathrm{X}+\mathrm{Y}+\mathrm{Z} ; \mathrm{X}=\mathrm{C} 2 \mathrm{H} 2$ $<300^{\circ} \mathrm{C} \quad \mathrm{C} 2 \mathrm{H} 4 \%=100 \mathrm{Y} / \mathrm{X}+\mathrm{Y}+\mathrm{Z} ; \mathrm{Y}=\mathrm{C} 2 \mathrm{H} 4$

T2: the zone of medium thermal $\quad \mathrm{CH} 4 \%=100 \mathrm{Z} / \mathrm{X}+\mathrm{Y}+\mathrm{Z} ; \mathrm{Z}=\mathrm{CH} 4$ fault $300<\mathrm{T}<700^{\circ} \mathrm{C}$ unit ppm

T3: the zone of high thermal fault $>700^{\circ} \mathrm{C}$

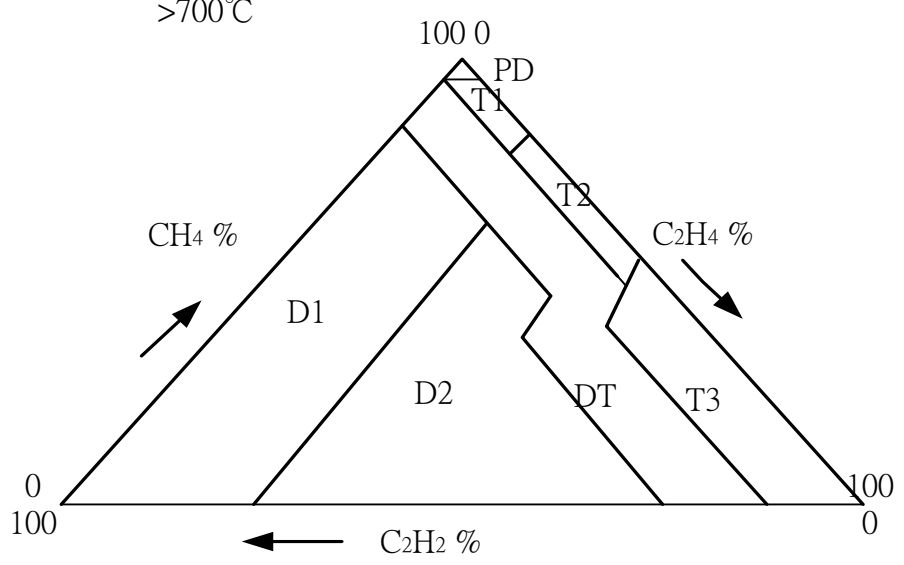

Figure 2. IEC-Duval triangle method [3]. 


\section{Transformer Fault Diagnosis}

\subsection{Specification ANSI/IEEE C57.104 Standards}

Be based on ANSI/IEEE C57.104 specification, the anomalous properties values from decomposition of the insulating oil were shown in Table 2.

\subsection{Linear SVM Diagnosis}

Japanese electric Association had cumulated 1033 transformers sets containing reactor to analysis since 1999 by linear regression method to obtain an insulating oil diagnostic method which was called "linear SVM (Support Vector Machine) diagnostic method”, the method will take $\mathrm{H}_{2}, \mathrm{CH}_{4}, \mathrm{C}_{2} \mathrm{H}_{6}, \mathrm{C}_{2} \mathrm{H}_{4}, \mathrm{C}_{2} \mathrm{H}_{2}$, and CO the component data into the formula via the value of the coefficient $(\mathrm{Z})$, to calculated and diagnose inside the transformer, the coefficients of the formula shown in Table 3.

When $\mathrm{Z}$ is "positive", which means transformer operation normal, Z is "negative”, which may operate abnormalities. The abnormality’s phenomenon was classified “Overheating”, "Electric Arc”, “Overheating + Discharge” and "Oil Mixes In” four kinds of fault type. If there are two or more of which expressed "negative” to show, you should use a larger value items interpret diagnostic analysis.

Formula:

$\mathrm{Z}=\mathrm{A} * \mathrm{H}_{2}+\mathrm{B} * \mathrm{CH}_{4}+\mathrm{C} * \mathrm{C}_{2} \mathrm{H}_{6}+\mathrm{D} * \mathrm{C}_{2} \mathrm{H}_{4}+\mathrm{E} * \mathrm{C}_{2} \mathrm{H}_{2}+\mathrm{F} * \mathrm{CO}+\mathrm{G} \quad$ (coefficient show in Table 3)

Table 2. Gas content in oil diagnostic [4] unit: ppm.

\begin{tabular}{cccccc}
\hline Name & Content value & Property & Name & Content value & Property \\
\hline & $>1801$ & Danger & & $>1001$ & Danger \\
$\mathrm{H}_{2}$ & $>701$ & Abnormal & & $>401$ & Abnormal \\
& $>101$ & Attention & & $>121$ & Attention \\
& $<100$ & Normal & & $<120$ & Normal \\
& $>151$ & Danger & & $>201$ & Danger \\
& $>101$ & Abnormal & & $>101$ & Abnormal \\
& $>66$ & Attention & $\mathrm{C}_{2} \mathrm{H}_{4}$ & $>51$ & Attention \\
$\mathrm{C}_{2} \mathrm{H}_{6}$ & $<65$ & Normal & & $<50$ & Normal \\
& $>35$ & Danger & & $>2$ & Attention \\
& $>10$ & Abnormal & & $<1$ & Abnormal \\
\hline $\mathrm{C}_{2} \mathrm{H}_{2}$ & & & & & \\
& & & & & \\
\hline
\end{tabular}

Table 3. Linear SVM discriminant formula and the A-G coefficient [5].

\begin{tabular}{cccccccccc}
\hline \multicolumn{8}{c}{$\mathrm{Z}=\mathrm{A} * \mathrm{H}_{2}+\mathrm{B} * \mathrm{CH}_{4}+\mathrm{C} * \mathrm{C}_{2} \mathrm{H}_{6}+\mathrm{D} * \mathrm{C}_{2} \mathrm{H}_{4}+\mathrm{E} * \mathrm{C}_{2} \mathrm{H}_{2}+\mathrm{F} * \mathrm{CO}+\mathrm{G}$} \\
\hline & formula & $(\mathrm{A}) \mathrm{H}_{2}$ & $(\mathrm{~B}) \mathrm{CH}_{4}$ & $(\mathrm{C}) \mathrm{C}_{2} \mathrm{H}_{6}$ & $(\mathrm{D}) \mathrm{C}_{2} \mathrm{H}_{4}$ & $(\mathrm{E}) \mathrm{C}_{2} \mathrm{H}_{2}$ & $(\mathrm{~F}) \mathrm{CO}$ & $\mathrm{G}$ & $\begin{array}{c}\text { Diagnosis } \\
\text { result }\end{array}$ \\
& $(3)$ & 0.01815 & -0.01365 & 0.02362 & -0.12971 & -7.32744 & 0.01223 & 2.21713 & Abnormal \\
& $(4)$ & - & - & - & -0.06095 & -11.21398 & - & 5.82626 & Abnormal \\
Coefficient & $(5)$ & 0.015052 & 0.032666 & -0.019081 & -0.034072 & 0.084326 & -0.002029 & 2.4662 & Overheating \\
& $(6)$ & 0.006088 & -0.046683 & 0.124659 & 0.015673 & -0.06937 & 0.016078 & -1.19747 & Electric Arc \\
& (7) & -0.010295 & -0.068228 & 0.023078 & 0.057307 & 0.16239 & 0.002373 & 0.79497 & Overheating + \\
Discharge
\end{tabular}




\section{The Heuristic Approach for in Practice}

\section{This Paper Follows the Design Flow Chart (Show in Figure 3)}

After the insulating oil was diagnosed by any way in research, based on takes accuracy and interpret graph of the establishment, as well as avoids misjudgment of the person. This paper designs a set of highly fast way to diagnose of transformer fault by The Key Gas rules and the standard of ANSI/IEEE the C57.104 diagnosis method. The decomposition chromatographic analysis (ASTM D3612) to produce nine kinds of gas, while we only took $\mathrm{CO}, \mathrm{H}_{2}, \mathrm{CH}_{4}, \mathrm{C}_{2} \mathrm{H}_{6}, \mathrm{C}_{2} \mathrm{H}_{4}$, and $\mathrm{C}_{2} \mathrm{H}_{2}$, for the data typed it in the application of program which will be carry out the result of diagnosis.

The program provides the man-machine interface, after the user inputs $\mathrm{CO}, \mathrm{H}_{2}, \mathrm{CH}_{4}, \mathrm{C}_{2} \mathrm{H}_{6}, \mathrm{C}_{2} \mathrm{H}_{4}$, and $\mathrm{C}_{2} \mathrm{H}_{2}$ gas content value on the program which takes on the reference date which is retyped so that yield a graph of test (real-line) with a graph of reference(virtual-line) to compare and analyze. Furthermore the correlation coefficients were compared with the two line range from -1 to +1 , if the value falls above +0.7 was considered extreme similarity. From the report's form obtains text of the ANSI/IEEE C57.104 standard diagnosis method and the graph of comparison (in Table 5) to judge what is in body for the transformer.

\section{Diagnostic Practices and Verification}

\subsection{NAN COU E/S \# 4ATr Case [6] [7]}

On October 19 th $^{\text {, }} 2012$ Taiwan Power Company Nan Cou E/S \# 4Atr's insulating oil, inspected these gas component content Hydrogen, Methane, Ethane, Ethylene, Acetylene, Carbon Monoxide, combustible gases and other gases total content data are described (in Table 4), this data (before repair and after repair) were used the Key Gas diagnosis rules, shown (in Tables 5 and 6) to obtain the result of the judgment by text of ANSI/IEEE standards and graphics of the Key Gas diagnosis rules.

How to diagnose the as result of transformer's insulating oil, form any gas quantity must to over the abnormal level and any one of correlation coefficient over +0.7 , so we can confirm having incipient faults and found the abnormal phenomenon of Overheating in.

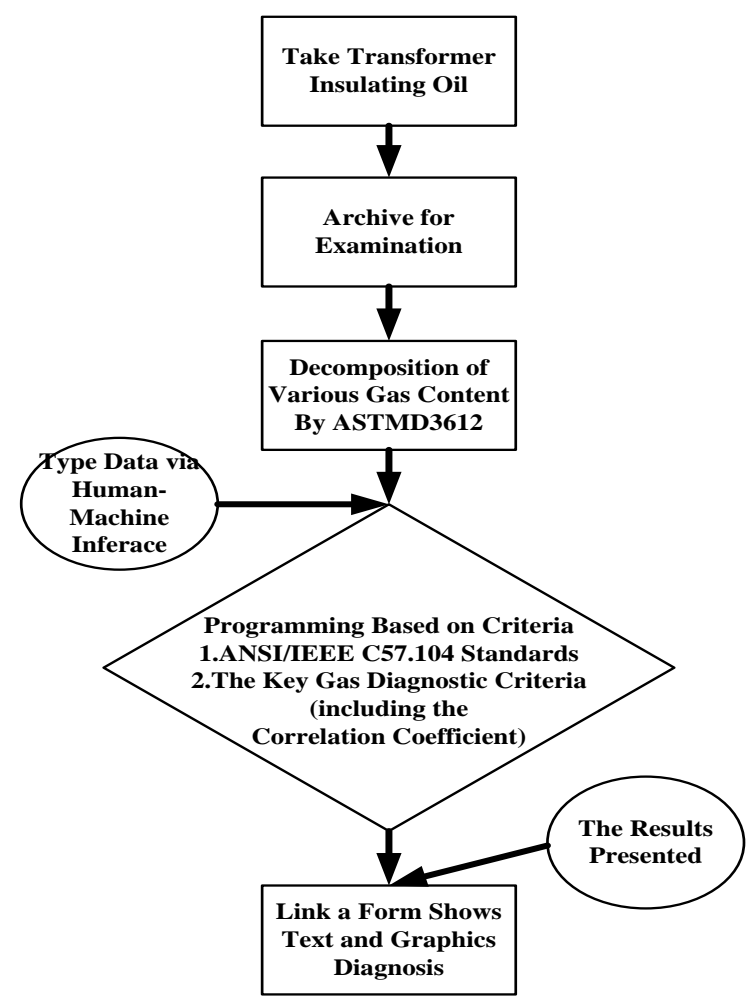

Figure 3. Diagnostic flowchart. 
Table 4. Nan Cou E/S \#4ATr gas data unit: ppm.

\begin{tabular}{cccccc}
\hline Date & $\mathrm{H}_{2}$ & $\mathrm{CH}_{4}$ & $\mathrm{C}_{2} \mathrm{H}_{6}$ & $\mathrm{C}_{2} \mathrm{H}_{4}$ & $\mathrm{C}_{2} \mathrm{H}_{2}$ \\
\hline 2012.10.19 Before repair & 174 & 602 & 216 & 643 & 2.6 \\
2012.12.12 After repair & 3 & 12 & 10 & 10 & 0.2 \\
\hline
\end{tabular}

Table 5. Test report by The Key Gas rules and the standard of ANSI/IEEE the C57.104 (before repair).

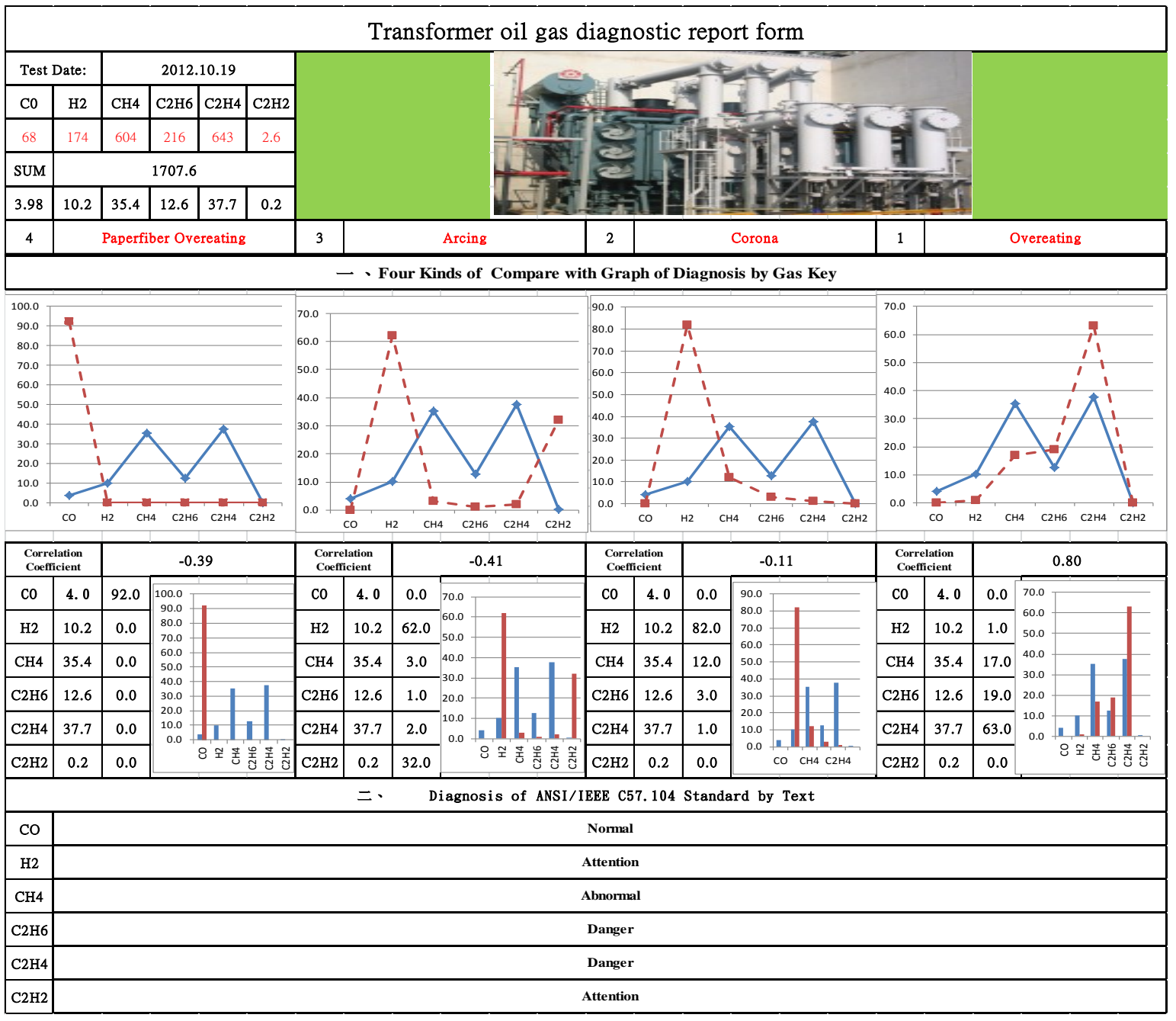

To ensure Southern Taiwan Science Park supply stable quality and safety of power considerations, on October $25^{\text {th }}, 2012$ Nan Cou E/S \#4Atr to fulfill the transformer body maintenance, found a screw melt with copper slag shown (in Figure 4) [6], this case to justify the Key Gas diagnosis rules of EXCEL program does provide a quick diagnosis of transformer fault, the results can be used as basis for transformer maintenance.

\subsection{Take Some Case to Confirm}

Taking some case (in Tables 7 and 8) for abnormality of transformer's insulating oil were confirmed from the last few pieces of Taiwan Power Company transformer insulating oil were due to the deterioration of the data to verify the practicality of the program.

\section{Conclusions}

In many papers, experts, scholars and senior engineers who deal in the abnormal of TCG of power a transformer 
Table 6. Test report by The Key Gas rules and the standard of ANSI/IEEE the C57.104 (after repair).

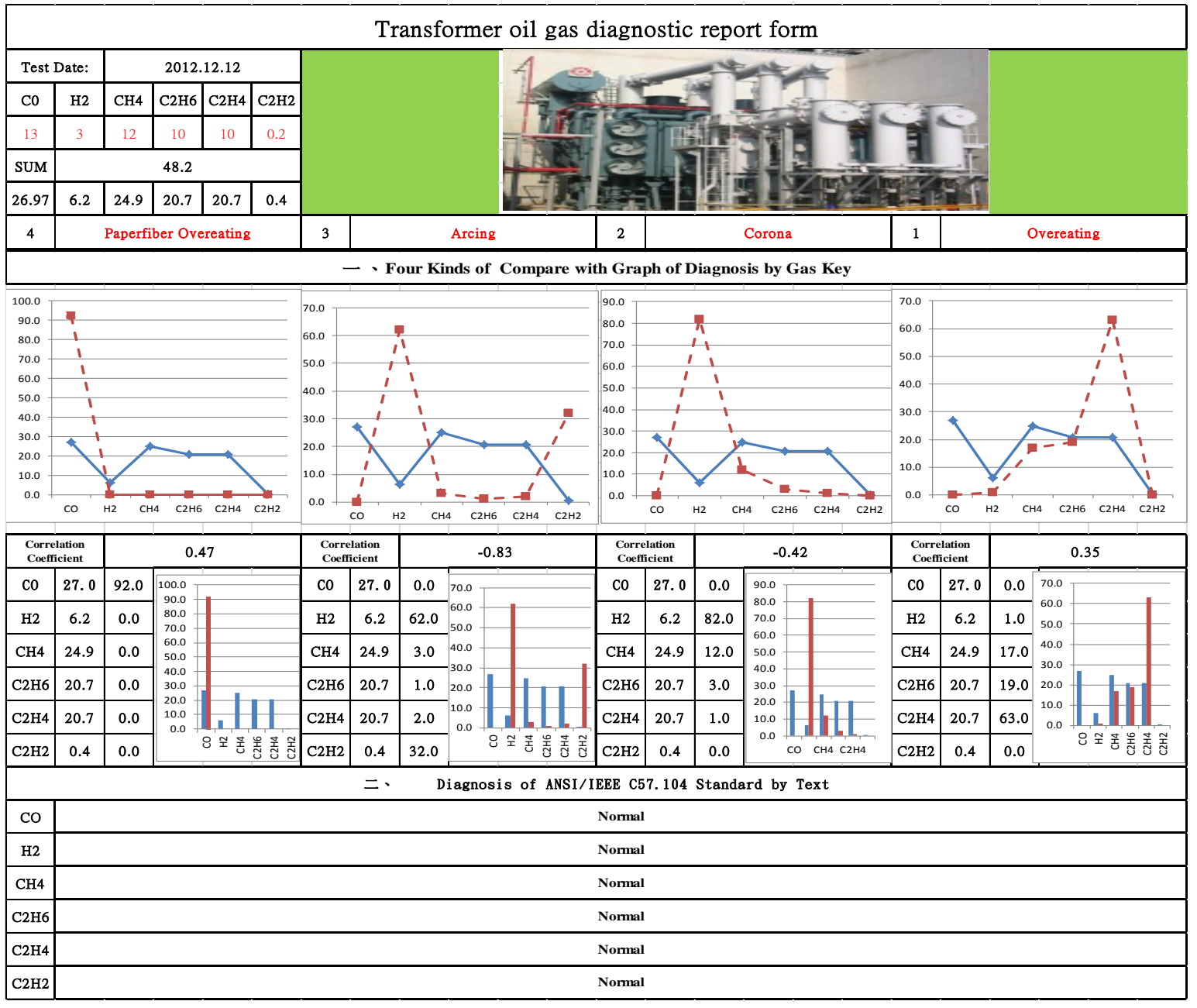

Table 7. Some in practical transformer gas data unit: ppm.

\begin{tabular}{ccccccc}
\hline Date & $\mathrm{CO}$ & $\mathrm{H}_{2}$ & $\mathrm{CH}_{4}$ & $\mathrm{C}_{2} \mathrm{H}_{6}$ & $\mathrm{C}_{2} \mathrm{H}_{4}$ & $\mathrm{C}_{2} \mathrm{H}_{2}$ \\
\hline $\mathrm{C} 1(2011.12 .26)$ & 128 & 935 & 271 & 116 & 330 & 420 \\
$\mathrm{C} 2(2012.05 .10)$ & 312 & 239 & 346 & 78 & 787 & 24 \\
$\mathrm{C} 3(2013.07 .08)$ & 36 & 48 & 694 & 356 & 1077 & 0.4 \\
$\mathrm{C} 4(2013.09 .23)$ & 411 & 133 & 211 & 66 & 384 & 1.9 \\
\hline
\end{tabular}

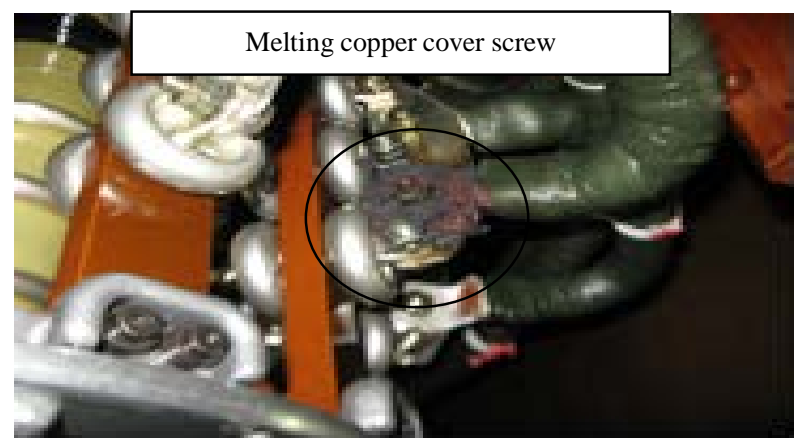

Figure 4. A Screw melting with copper. 
Table 8. In practical implementation of the results.

\begin{tabular}{ccccccccc}
\hline & \multicolumn{3}{c}{ ANSI/IEEE Text } & \multicolumn{5}{c}{ Fault-type for Key Gas } \\
\hline NAME & C1 & C2 & C3 & C4 & C1 & C2 & C3 & C4 \\
\hline $\mathrm{CO}$ & $\mathrm{N}$ & $\mathrm{N}$ & $\mathrm{N}$ & At & & & & \\
$\mathrm{H}_{2}$ & A & At & $\mathrm{N}$ & At & & & & \\
$\mathrm{CH}_{4}$ & At & At & A & At & & & & \\
$\mathrm{C}_{2} \mathrm{H}_{6}$ & A & At & D & At & Co \& Ar & Ov & Ov & Pa \\
$\mathrm{C}_{2} \mathrm{H}_{4}$ & D & D & D & D & & & & \\
$\mathrm{C}_{2} \mathrm{H}_{2}$ & D & A & N & N & & & & \\
\hline
\end{tabular}

Symbols: N (Normal), A (Abnormal), At (Attention), D (Danger), Co (Corona), Ar (Arcing), Ov (Overheating), Pa (Paper Fiber Overheating), C1 (Case1), C2 (Case2), C3 (Case3), C4 (Case4).

which is so complicated that it's difficult to distinguish because the amount of the element of gas and the ratio of gas are variables influences of diagnose, so how to judge that takes experiences to make accurate but it is more important for usage a highly and simply diagnosis method it must.

From on October $25^{\text {th }}$, 2012 Nan Cou E/S \# 4 ATr transformer testing in practices validated that the Key Gas diagnosis rules really easy to use at any condition of transformer for analysis, while improved the accuracy of diagnosis as well as up the quality and stability of transformer and settled the information of operation.

The approach diagnosis technique aims to diagnose the gas-in-oil concentration measurements which were decomposed via the instrument of ASTM D3612 from transformer's insulating oil the best accuracy and misjudgment possible. The gases consist that we can so easy to investigate what kind fault of transformer that manage the equipment from a report form justly.

\section{Acknowledgements}

The relevant information for this paper was provided by the department of the supply, Chan Nan breach supply, researcher Institute of Taiwan Power Company, and Future Electric Co., Ltd., Only to say thanks here.

\section{References}

[1] IEEE (2012) C57.104-IEEE Guide for the Interpretation of Gases Generated in Oil-Immersed Transformers. Minutes of WG Meeting Nashville, Tennessee.

[2] IEC (1999) Guide to the Interpretation of Dissolved and Free Gasses Analysis. IEC Standard 60599, IEC Publ.

[3] Singh, S. and Bandyopadhyay, M.N. (2010) Duval Triangle: A Noble Technique for DGA in Power Transformers. International Journal of Electrical and Power Engineering, 4, 193-197. http://dx.doi.org/10.3923/ijepe.2010.193.197

[4] Mollman, A. and Pahlavanpour, B. (1999) New Guidelines for Interpretation of Dissolved Gas Analysis in Oil-filled Transformers. Electra, CIGRE France, 186, 30-51.

[5] Electric Cooperative Research Council (2013) The Revised Guidelines of Power Transformers. No. 1 (Heisei 21 years).

[6] Qi, Y.G., Ming, L.K., Sing, G.B., Sung, S.U. and Xia, S. (2012) Nan Cou E/S \#4 ATr overhaul Report. Taiwan Power Company Institute.

[7] Than, C.F., Qing, C.J. and Than, L.Y. (2012) Nan Cou E/S \# 4 ATr overhaul Report. Future Electric Co., Ltd. 